\title{
The perception of healthcare quality of elderly in the city of Bari, South Italy
}

\author{
Rosa Prato $^{\dagger 1}$, Domenico Martinelli ${ }^{\dagger 2}$, Annarita Fusco ${ }^{2}$, Annarita Panebianco ${ }^{2}$, \\ Pietro Luigi Lopalco ${ }^{2}$, Cinzia Annatea Germinario*2 and Michele Quarto ${ }^{2}$
}

\author{
Address: ${ }^{1}$ Section of Hygiene Department of Scienze Mediche e del Lavoro, University of Foggia, Foggia, Italy and ${ }^{2}$ Section of Hygiene Department \\ of Scienze Biomediche e Oncologia Umana, University of Bari, Bari, Italy \\ Email: Rosa Prato - r.prato@unifg.it; Domenico Martinelli - domenicomartinelli@gmail.com; Annarita Fusco - specializzandi@igiene.uniba.it; \\ Annarita Panebianco - specializzandi@igiene.uniba.it; Pietro Luigi Lopalco - Pierluigi.Lopalco@ecdc.europa.eu ; \\ Cinzia Annatea Germinario* - c.germinario@igiene.uniba.it; Michele Quarto - m.quarto@igiene.uniba.it \\ * Corresponding author †Equal contributors
}

Published: 24 October 2007

BMC Health Services Research 2007, 7:174 doi:10.1 186/1472-6963-7-174

Received: 4 April 2007

Accepted: 24 October 2007

This article is available from: http://www.biomedcentral.com/1472-6963/7/I74

(c) 2007 Prato et al; licensee BioMed Central Ltd.

This is an Open Access article distributed under the terms of the Creative Commons Attribution License (http://creativecommons.org/licenses/by/2.0), which permits unrestricted use, distribution, and reproduction in any medium, provided the original work is properly cited.

\begin{abstract}
Background: In recent decades in Italy, as in all the industrialized nations, the proportion of elderly subjects in the total population is constantly on the increase. However the increased life expectancy is not always paralleled by a true improvement in the quality of life.

In this context, it is essential to analyze elderly real health needs and the responses to these needs, especially in terms of healthcare, that the territorial services are perceived to offer.

Methods: In the period from June to September 2006 we selected randomly one General Practitioner (GP) for each district of the Bari Municipal Area and, form each GP, we randomly chose 25 patients over 65 years old (YO). We conducted phone interviews using a standard data collection questionnaire and, for each of the recruited subjects, the GP filled a data collection sheet.

Results: Although the mean age (73.6 years) of the population under study was quite high, the general state of health was judged good both by the G P- and by their elderly patients (>75\%).

Notably, the great majority of elderly patients considered the healthcare they receive to be satisfactory (>60\%): in particular, the GP was the true point of reference for this slice of the population for strictly medical problems as well as for advice. On the contrary, the patients attributed little value to social services, which were poorly known and scarcely used (8.5\%). Public hospital facilities played a central role in second level healthcare in more than $30 \%$ of cases; private facilities covered by public health insurance were also very important. As possible solutions to the problem of loneliness, $36.6 \%$ of the patients declared that they approved of nursing homes.
\end{abstract}

Conclusion: Decision makers need to create services supporting the key role played by General Practitioners, who are well aware that their assistance is not sufficient to satisfy the health needs of the elderly. 


\section{Background}

In recent decades in Italy, as in all the industrialized nations, the proportion of elderly subjects in the total population is constantly increasing. The progressive aging of the population is the result of profound demographic changes that include both a falling birth rate and a consistent decline in the mortality rates for all causes [1-4].

Life expectancy at 60 years of age has increased by 2 years in the last 2 decades, and the number of people over 75 years of age has thus risen in the same period by $33.7 \%$, nearly twenty fold higher than the overall increase in the Italian population $(1.8 \%)$. Italy is the first nation in the world where the percentage of elderly subjects has exceeded that of young people less than 15 years of age $(17.3 \%$ vs $14.5 \%)$. In the future this difference will surely widen. It is estimated that in the next ten years the number of young people between 15 and 34 years of age will decline by about 5 million due to declining fertility rates, while the number of elderly people will rise by 1.5 million. This progressive population aging is expected to reach a peak in 2030, the year when there are expected to be 15 million people over 75 years of age in Italy, accounting for $28 \%$ of the population [5]. This increased life expectancy is not paralleled by improvements in the quality of life, because advancing age often goes hand in hand with a loss of autonomy, aggravated by the presence of multiple disease and a condition of social isolation [6$13]$.

There is a widely felt need to explore the "world of senior citizens", to define the socio-demographic characteristics of this large slice of the population, identify their needs and provide decision makers with useful, efficacious support for political actions [14-16].

In this context, therefore, besides an objective and subjective investigation of the health of the elderly, it is essential to analyze their real health needs and the response to these needs, especially in terms of healthcare, that the territorial services are perceived to offer [17]. In the present study, this assessment has been made by comparing the subjective experience of patients over 65 years of age with that of their General Practioner (GP), who takes the main role in primary health care of elderly, in Italy [18-21].

\section{Methods}

In the period June - September 2006 we performed a cluster sampling study among the GPs and their populations of registered patients over 65 years of age resident in the Bari Municipality Area. One GP for each municipal district $(\mathrm{N}=15)$ was selected. 25 subjects aged over 65 years were selected from 11 of the 15 GP, 16 subjects from 1 GP, 15 subjects from 2 GPs, 10 subjects from 1 GP, making up a total sample of 331 subjects. In Italy every GP cannot take care of more than 1,500 patients aged more 14 years (people $\leq 14$ years are followed by family paediatricians); therefore they can have a number of patients less than 1,500. For those GPs with less than 1,500 registered patients, the number of patients represented about $2.5 \%$ of the total number of patients over 65). All the GPs and subjects were selected randomly.

The investigation was conducted by phone interview using a standard data collection questionnaire administered to each study subject, after obtaining informed consent. For each of the recruited subjects, the GP filled a data collection sheet. In the patients study sample, the questions regarded the perception of their psychophysical state of health, present disabilities, drugs prescribed, health assistance received [22-25]. The first part of the questionnaire indicated the name of the person who answered the telephone (study subject or, in cases of severe physical and/or mental disability, another subject) and the personal details of the enrolled subject.

The following sections were included in the questionnaire:

- state of health;

- loneliness;

- drugs taken and administration route;

- disabilities and autonomy in carrying out daily activities;

- degree of satisfaction with healthcare received;

- knowledge of available health services (health benefit contribution to supply drugs, integrated home assistance, emergency phone service, etc);

- frequency and type of consultation of the GP;

- method, frequency and facility consulted for analyses and other diagnostic tests;

- method, frequency and facility consulted for specialist visits and physiotherapy.

In the same context, possible areas of intervention and initiatives serving to better respond to the identified needs were investigated: opinions on facilities like nursing homes, knowledge of the concept of "group apartment", frequency of recreation activities, proposals for improving the situation.

At the same time, the GPs' opinions of the same topics were assessed (every GP were answering questions about 
each of his own patients). The questionnaire included 10 topics:

- state of health of the patient;

- main disabling disease/s;

- frequency and reason for ambulatory visits;

- degree of satisfaction with the healthcare received by the patients;

- facility consulted for laboratory tests, instrumental investigations and specialist visits, and reason for their choice;

- need and indication for other types of assistance, apart from those supplied.

GPs were not allowed to access to their patient interviews. In the same way, the patients did not know about GPs opinions.

The data collected were stored in a database built with File Maker Pro 7.0 software for MacOs X and processed with Epi Info 3.3. Prevalence rates and 95\% confidence intervals $(95 \% \mathrm{CI})$ were calculated taking into account the design effect due to the cluster sampling [26]. Epi Info 6.0.4 software was used for calculation. Contingency tables were plotted for comparisons between categorical variables, calculating the Chi square $\left(\chi^{2}\right)$ value; values of $\mathrm{p}$ $<0.05$ were considered significant.

\section{Results \\ Study population}

The National Statistics Institute current data for 1 January 2005 were used to estimate the sample size of elderly (over 65) resident in the Bari municipality [27]. The total population of over 65 year olds resident in the Bari municipality equals 59,500 people $(18.1 \%$ of the general population).

The study sample consisted of 15 GPs and 331 elderly patients. GPs were not able to answer about 16 patients, therefore the final number of questionnaires completed by GPs was 315 . Patients' willingness to participate in the study was high: only $4.8 \%$ refused consent, while a person other than the subject answered for $34.1 \%$ of the subjects enrolled.

Patients mean age was 76.3 years (median $=75$ years; mode $=72, \mathrm{SD}= \pm 6.08$; range: $66-98) ; 53.8 \%$ were male and $46.2 \%$ female (Table 1 ); $62.5 \%$ were married, $28.7 \%$ widowed, $6 \%$ unmarried, $2.7 \%$ divorced; $51 \%$ lived with their spouse, $20.3 \%$ with a son/daughter, $18 \%$ alone, $3.4 \%$ with a carer $(7.3 \%$ with others); $38.7 \%$ had attended
Table I: Sample distribution, by sex and age

\begin{tabular}{ccccccc}
\hline & \multicolumn{2}{c}{ Female } & \multicolumn{2}{c}{ Male } & \multicolumn{2}{c}{ Total } \\
\cline { 2 - 7 } Age & $\mathrm{N}$ & $\%$ & $\mathrm{~N}$ & $\%$ & $\mathrm{~N}$ & $\%$ \\
\hline $65-74$ & 71 & 46.4 & 79 & 44.38 & 150 & 45.32 \\
$75-84$ & 66 & 43.1 & 76 & 42.70 & 142 & 42.90 \\
$\geq 85$ & 16 & 10.5 & 23 & 12.92 & 39 & 11.78 \\
\hline Total & 153 & - & 178 & - & 331 & - \\
\hline
\end{tabular}

primary school, $19.9 \%$ middle school, $16.9 \%$ high school, $12.4 \%$ a university, while $12.1 \%$ had no scholastic attendance certificate. As to working activities, about one third of the sample were housewives $(29.6 \%), 70.5 \%$ declared that they received a retirement pension, $24.5 \%$ social benefit and 5\% a carer contribution.

\section{State of health}

Among the patients, $27.8 \%$ defined their state of health as good or very good, $49.2 \%$ (95\% CI: 45.6-52.9) as moderate and $21.5 \%$ (95\% CI: $16.9-26.7)$ as poor; $1.2 \%(95 \%$ CI: 0.2-4.9) answered "I don't know". For their GPs $2.9 \%$ (95\% CI: $0-5.9)$ of the selected sample was in very good, 26\% (95\% CI: 16.6-35.4) in good, 51.4\% (95\% CI: $43.7-$ 59 ) in moderate and $18.4 \%$ in poor health (95\% CI: $11.9-$ 24.9); $1.3 \%$ (95\% CI: $0.2-4.9)$ answered "I don't know". The difference between the perception of health of the patients and their GPs was not significant ( $p>0.05$ - Table $2)$. The most frequently diagnosed disease was hypertension (57\%; 95\% CI: 52.6-62.1), followed by arthritis (38.7\%; 95\% CI: 30.4-47.6), cardiovascular disease (32.6\%; 95\% CI: 26.4-39.5), diabetes (19.3\%; 95\% CI: $14.2-25.7)$, respiratory diseases $(15.7 \%, 95 \%$ CI: $11.3-$ $21.3 \%)$.

Limitations to carry on any activities (indoor and outdoor) due to a health problem were referred by $61.9 \%$ (95\% CI: 53.3-69.8) of the patients. According to the patients, the main health problems causing these limita-

Table 2: State of health, by patients and GPs opinion

\begin{tabular}{lrrrr}
\hline & \multicolumn{2}{c}{ Patients } & \multicolumn{2}{c}{ GPs } \\
\cline { 2 - 5 } State of health & $\mathrm{n}$ & $\%(95 \% \mathrm{Cl})$ & $\mathrm{n}$ & $\%(95 \% \mathrm{Cl})$ \\
\hline Very good & 21 & $6.3(3.7-10.6)$ & 9 & $2,9(0-5.9)$ \\
Good & 73 & $21.7(18-26)$ & 82 & $26(16.6-35.4)$ \\
Moderate & 166 & $49.2(45.6-52.9)$ & 162 & $51.4(43.7-59)$ \\
Poor & 71 & $21.4(16.9-26.7)$ & 58 & $18.4(I 1.9-24.9)$ \\
Don't know & 4 & $1.2(0.2-4.9)$ & 4 & $1.3(0.2-4.9)$ \\
\hline Total & 331 & -315 & - \\
\hline
\end{tabular}


tions are: arthrosis (in particular, problems in walking) for $43.5 \%$ (95\% CI: 37.4-49.8) of the sample, poor sight for 14.2 (95\% CI: 8.6-22.4) and hearing for 9.4\% (95\% CI: 5-16.4), hypertension for $12.7 \%$ (95\% CI: 8.5-18.2). According to their GPs, the main causes of disability are hypertension in 52.6\% (95\% CI: 44.9-60.2) of cases, arthrosis (in particular, problems in walking) in 19\% (95\% CI: $13.9-25.4$ ), heart problems in $29.8 \%$ (95\% CI: 22-38.9), depression in $18.9 \%$ (95\% CI: 12.6-25.1), diabetes in $18.1 \%$ (95\% CI: $14.6-22.1$ ). There is a significant difference between the GPs' and the patients' opinions $\left(\chi^{2}\right.$ $=188.27, \mathrm{p}<0.001-$ Figure 1$)$.

\section{Loneliness}

When asked about feeling lonely, 9.7\% (95\% CI: 5.615.9) of the patients interviewed reported that they felt lonely "always", 45.6\% (95\% CI: 34.7-56.9) "sometimes", while 35\% (95\% CI: $28.7-42$ ) declared that they "never" felt lonely. 9.7\% (95\% CI: 5.5-16.1) answered "I don't know".

\section{Drugs}

78.2\% (95\% CI: 71.9-83.5) of the sample is under pharmacological therapy following their doctor's instructions: daily by $78,2 \%$ of the patients, periodically by $4.8 \%$, at need by $11.3 \%$. The remaining $5.7 \%$ did not answer the question. Some changes in the prescribed regimen were introduced by $14.2 \%$ (95\% CI: $10-19.6)$ of those interviewed, while $4.2 \%$ (95\% CI: $2-8.2$ ) did not follow the GPs' instructions because too "many drugs are considered harmful" (50\%), "not all are equally useful" (12.5\%), because the patient forgot to take them (33.3\%) or other $(4.2 \%)$. The drugs most frequently taken without a medical prescription were: NSAIDS (81.5\%), gastroprotectors, antidiabetics and laxatives (all in 3,1\% of cases), antihypertensives, vasoprotectors and antibiotics (all in 1.5\% of cases), all types of drugs (4.7\%). 3.4\% (95\% CI: 1.6-6.5) didn't answer the question.

\section{Disabilities}

12.7\% (95\% CI: 8.4-18.6) of the patients see well, while, due to declining sensory powers, $72.8 \%$ (95\% CI: $65.3-$ 79.2 ) need glasses to see well, $11.8 \%$ (95\% CI: 8.5-16.1) refer that they cannot see well and $2.7 \%$ (95\% CI: 1.4-5) have serious sight impairment. $67.7 \%$ of the sample $(95 \%$ CI: 59.5-74.9) hears well, while $25.4 \%$ (95\% CI: $19.8-$ 31.9 ) have difficulty in hearing and $6.9 \%$ (95\% CI: $3-$ 14.2 ) are frankly "deaf". In addition, 67\% (95\% CI: 58.174.9) of cases do not have difficulty in chewing harder foods, $24.6 \%$ (95\% CI: $19.1-30.7)$ have difficulty, and $8.4 \%$ (95\% CI: $4.1-16)$ are unable to do so.

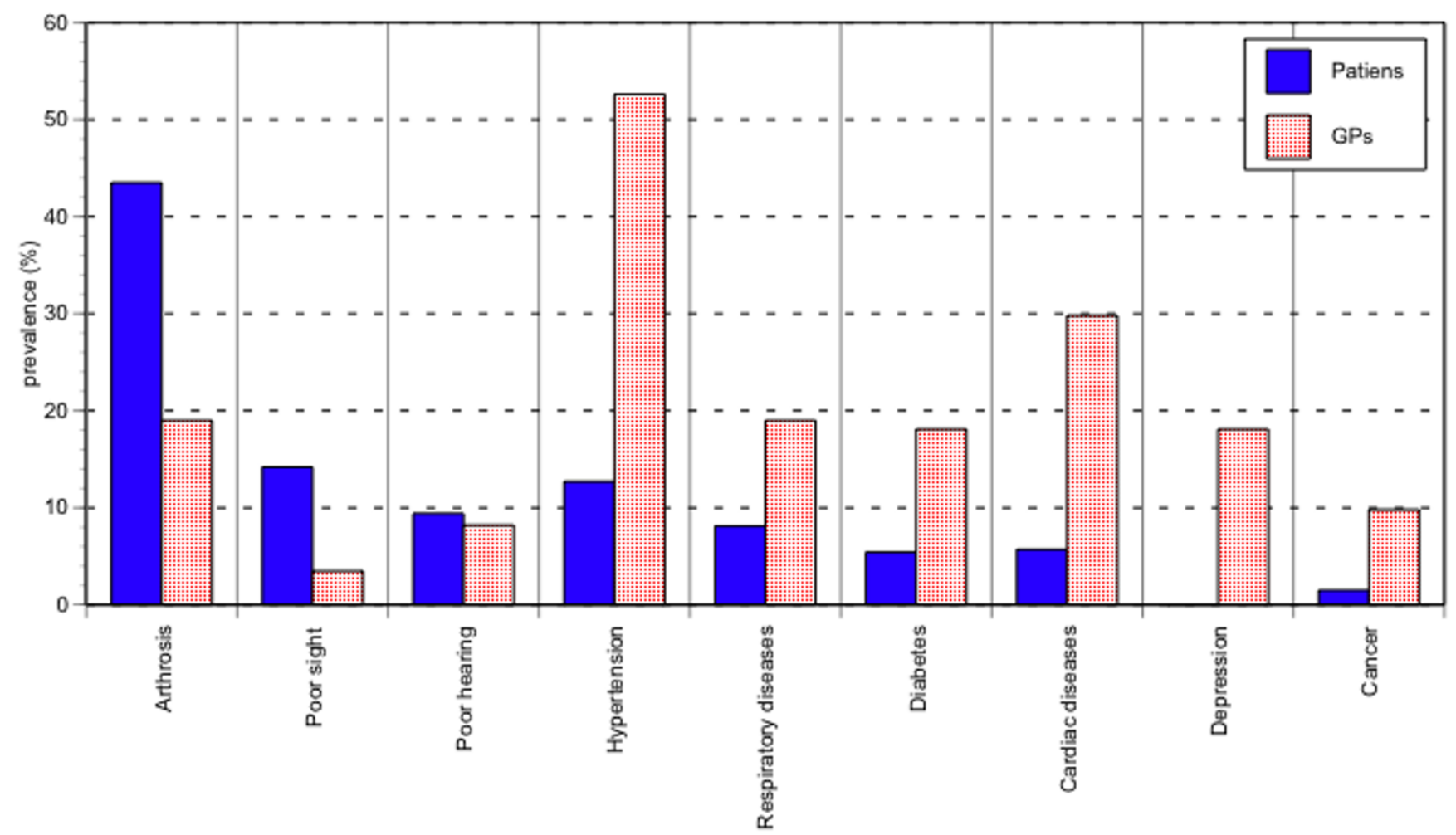

Figure I

Distribution of diseases defined as limiting, by the patient and by the GP. 
As regards daily activities, $8.7 \%$ (95\% CI: $6.5-11.7)$ of the sample need help to move from one room to another, $10.3 \%$ (95\% CI: 8.1-12.9) to go to the bathroom, $11.9 \%$ (95\% CI: $8.4-16.2)$ to wash, $18.7 \%$ (95\% CI: $13.6-23)$ to take a bath or shower, $15.1 \%$ (95\% CI: $11.3-19.8)$ to dress, $14.2 \%$ (95\% CI: 11.3-17.6) to climb up/down the stairs. They receive help from a son/daughter in 39.6\% and from their spouse in $30.8 \%$ of cases, $21,6 \%$ from others. Although only $21.8 \%$ (95\% CI: $14-31.9$ ) referred regular physical activity, 55.6\% (95\% CI: 46.3-64.5) of the sample goes out every day and $68.6 \%$ of the latter declared that they do not need to be accompanied.

\section{Assessment of healthcare}

Among the patients, $17.5 \%$ (95\% IC: $11-26.4)$ rated the healthcare they receive as very good, $43.1 \%$ (95\% IC: 35.2-52.1) as good, 28.7\% (95\% IC: 22.4-35.9) as moderate, $7.8 \%$ (95\% IC: $4.5-13.2)$ as poor; $3.6 \%$ (95\% IC: 1.6-6.5) did not know how to answer the question. According to their GPs, $16.5 \%$ (95\% IC: 6-35.8) of the patients are very satisfied with the healthcare received, 57.5\% (95\% IC: 46.1-67.5) are moderately satisfied, 2.2\% (95\% IC: $0.8-5.5)$ are dissatisfied; the GP cannot give an opinion about $23.2 \%$ (95\% IC: $13.5-36.4$ ) of cases. There is a significant difference between these answers $\left(\chi^{2}=76.1, \mathrm{p}<0.001\right)$, partly due to the GPs' difficulty in judging their patients' opinions (Table 3 ).

\section{Social Services}

As regards patients' knowledge of health assistance, $8.9 \%$ (95\% IC: 5.3-14.4) know about health benefits, $23.9 \%$ (95\% IC: 19.7-28.6) about home care service integrated and 43.2\% (95\% IC: 35.4-51.3) about emergency telephone assistance. Recourse to the municipal social services was made by $7.6 \%$ (95\% IC: 4.7-11.7) of the patients. Among them 42.9\% were satisfied with the attention received, whereas $39.3 \%$ complained of long waiting lists and bureaucratic difficulties; the remaining $17.8 \%$ of the subjects interviewed did not know how to answer the question.

\section{General Practitioners}

In the last year, $1.8 \%$ (95\% CI: 0.3-7.2) of the interviewed patients needed to visit their GP every day - this figure was $0.6 \%$ (95\% CI: $0.1-2.1$ ) according to the GPs $14.5 \%$ (95\% CI: $8.4-23.5)$ of cases once a week - 10.5\% (95\% CI: 5.3-19.1) according to the GPs, $54.1 \%$ (95\% CI: $47.2-$ 60.8) of cases once a month - 33\% (95\% CI: 24.9-42.2) according to the GPs, $17.5 \%$ (95\% CI: 13-23.1) of cases at least once every 3 months - 24.1\% (95\% CI: $18.7-$ $30.4)$ according to the GPs, $6.6 \%$ (95\% CI: $4-10.7)$ of cases once every 6 months - 13.7\% (95\% CI: 7.8-22.6) according to the GPs, $4.6 \%(95 \% \mathrm{CI}: 2.8-7.2)$ of cases never - 18.1\% (95\% CI: $12.7-24.2)$ according to the GPs; $0.9 \%$ (95\% CI: 0.4-2) didn't answer the question. There is a significant difference between the answers given by the patients and the ones given by their GPs $\left(\chi^{2}=58.3, \mathrm{p}\right.$ $<0.001)$.

For the patients, the main reasons for going to their GP were the onset of new symptoms in 30.5\% (95\% CI: $23.2-$ 38.8 ) of cases $-37.5 \%$ (95\% CI: $25.3-51.4$ ) according to the GPs; known diseases in $47.1 \%$ (95\% CI: 40.7-53.6) of cases $-48.5 \%$ (95\% CI: 35.6-61.7) according to the GPs; drug prescriptions in $83.1 \%$ (95\% CI: 72.1-90.4) of cases - $47.6 \%$ (95\% CI: 32.6-63) according to the GPs; to ask advice in $10.9 \%$ (95\% CI: $6.3-17.9$ ) of cases - $26.3 \%$ (95\% CI: 15-41.5) according to the GPs. Again, there was a significant difference between the opinions of the two groups $\left(\chi^{2}=38.2, \mathrm{p}<0.001-\right.$ Table 4$)$.

Contacts with the GP were by telephone for 40\% (95\% CI: $30.7-49.8$ ) of the sample, at the ambulatory office for $68.9 \%$ (95\% CI: 62.8-74.4), by home visit for $16.9 \%$ (95\% CI: 7.8-31.9), while a person other than the patient went to the doctor for $16.6 \%$ (95\% CI: 12.1-22.3) of the sample. $51.9 \%$ (95\% CI: 46.2-57.7) of the patients declared that they were satisfied with their GP's medical care, while reasons for dissatisfaction or dissuading the patient from applying to the GP were long waiting times (12.1\%; 95\% CI: 8.8-16.2), inconvenient opening hours

Table 3: Assessment of healthcare, by patients and GPs' opinion

\begin{tabular}{|c|c|c|c|c|}
\hline \multirow[b]{2}{*}{ Assessment of healthcare } & \multicolumn{2}{|c|}{ Patients } & \multicolumn{2}{|c|}{ GPs } \\
\hline & $\mathrm{n}$ & $\%(95 \% \mathrm{Cl})$ & $\mathrm{n}$ & $\%(95 \% \mathrm{Cl})$ \\
\hline Very good & 54 & $17.5(\mid I-26.4)$ & 52 & $16,5(6-35.8)$ \\
\hline Good & 144 & $43.5(35.2-52.1)$ & & \\
\hline Moderate & 95 & $28.6(22.4-35.9)$ & 181 & $57,1(46.1-67.5)$ \\
\hline Poor & 26 & $7.8(4.5-13.2)$ & 7 & $2,2(0.8-5.5)$ \\
\hline Don't know & 12 & $3.6(1.6-6.5)$ & 75 & $23,2(13.5-36.4)$ \\
\hline Total & 331 & - & 315 & \\
\hline
\end{tabular}


Table 4: Main reasons why patients need to visit their GP, by patients and GPs' opinion

\begin{tabular}{lrr}
\hline & Patients & \multicolumn{1}{c}{ GPs } \\
\hline Main reasons & Prevalence \% (95\% Cl) & Prevalence \% (95\% Cl) \\
\hline To ask advise & $10.9(6.3-17.9)$ & $26.3(I 5-4 I .5)$ \\
Known diseases & $47.1(40.7-53.6)$ & $48.5(35.6-61.7)$ \\
Drug description & $83.1(72.1-90.4)$ & $47.6(32.6-63)$ \\
New symptoms & $30.5(23.2-38.8)$ & $37.5(25.3-5 I .4)$ \\
Number of answers & 331 & 315 \\
\hline
\end{tabular}

(2.4\%; 95\% CI: 0.76-6.6), the distance from home (4.83\%; 95\% CI: 2.3-9.4).

\section{Laboratory tests, instrumental investigations, specialist visits, physiotherapy}

In the previous year, 55\% (95\% CI: 47.1-62.6) of the patients had undergone a laboratory and/or instrumental test at least once every 6 months, and 43.8\% (95\% CI: 36.3-51.6) had had a specialist visit at least once. Again in the previous year, most of the patients $(82,2 \% ; 95 \% \mathrm{CI}$ : 77.8-85.8) did not undergo or did not need physiotherapy, while 7.5\% (95\% CI: 5.6-10) had undergone at least one session (Figure 2).

Routine laboratory tests were done in a public facility (For laboratory tests hospital and public facility were considered all together) for nearly 42.5\% (95\% CI: 34.3-51.3) of the patients, mainly because they followed the GP's advice $(29.8 \%)$ or had more confidence in it (31.2\%); private facilities covered by public health insurance were used by $27.5 \%$ (95\% CI: 21.3-34.7): because they were
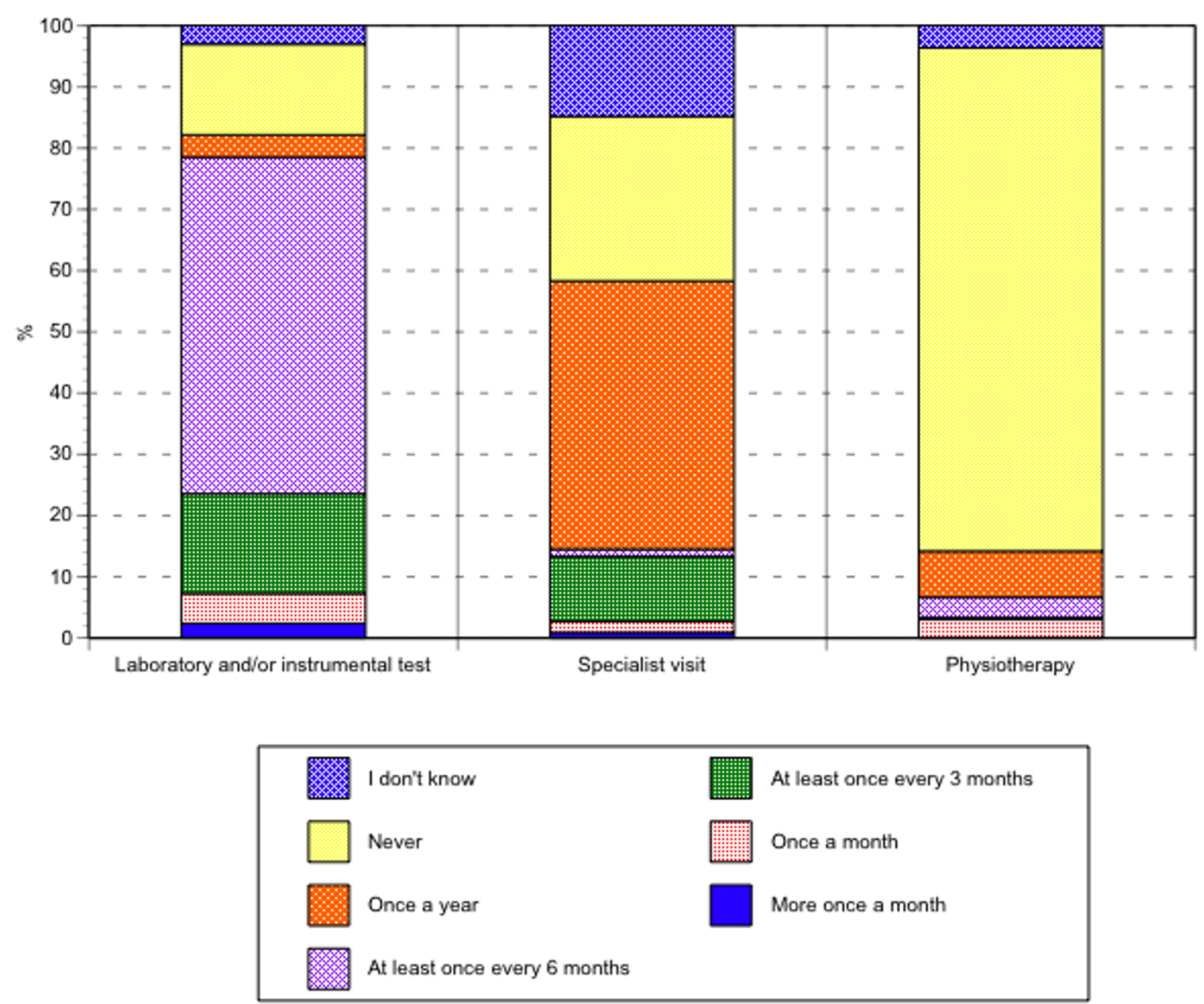

Figure 2

Percentage distribution of recourse to laboratory, diagnostic-instrumental tests, specialist visits, physiotherapy cycles. 
nearer home for $41.8 \%$ of the sample, or were indicated by the GP (28.6\%); the 13.9\% (95\% CI: 9.9-9.1) of the sample consulted a private facility, largely because they thought waiting lists were shorter $(34 \%)$, or because the facility was nearer home (34\%).

Diagnostic-instrumental tests were performed at a hospital facility for $29.9 \%$ (95\% CI: $26-34)$ of the patients because they had more confidence in it (32.3\%), because it was advised by the GP (25.3\%); at a private facility covered by public health insurance for $17.8 \%$ (95\% CI: $12.6-$ 24.5), largely because they thought waiting lists were shorter $(27.3 \%)$, because it was advised by the GP $(10.2 \%)$ or the facility was nearer home $(12.6 \%)$; at a public "territorial" facility for 13.3\% (95\% CI: 8.7-19.6) because it was advised by the GP (43.2\%) or was nearer home (22.7\%). The 13.29\% (95\% CI: 8.6-19.7) of the sample went to a private facility because they had more confidence in it (38.6\%) and thought the waiting lists were shorter (34.1\%).

The specialist most frequently consulted was the cardiologist in $29.8 \%$ of cases, followed by the ophthalmologist in $16.3 \%$ of cases, the orthopedic surgeon in $11 \%$ and the urologist in $8.2 \%$ of cases; other specialists (the oncologist, endocrinologist, physiatrist, etc.) were consulted in $34.7 \%$ of cases.

For the specialist visit, 29\% (95\% CI: 24.9-33.4) of the sample went to a hospital facility, mainly because they had more confidence in it $(43.8 \%)$ or it was advised by the GP (28.1\%). Instead, 20.5\% (95\% CI: 16.3-25.4) went to a private facility because it was advised by the GP $(36.8 \%)$ or they had more confidence in it $(33.8 \%)$. A public territorial facility was chosen by $13.9 \%$ (95\% CI: $10.1-18.7$ ) of the sample because it was advised by the GP $(41.3 \%)$ or nearer home $(21.7 \%)$. The $7.8 \%$ of the sample $(95 \% \mathrm{CI}$ 5.3-11.3) consulted a specialist at a private facility covered by public health insurance because they found shorter waiting lists or it is near home (19.2\%) or it was advised by the GP (26.9\%).

For a physiotherapy cycle $8.1 \%$ (95\% CI: 5.9-11.1) of the sample chose a private facility covered by public health insurance because it was nearer home $(38.5 \%)$ or advised by the GP (23.1\%), while $1.2 \%$ (95\% CI: 0.5-2.6) preferred a private facility because they had more confidence in it $(100 \%)$ or because it was advised by the GP $(75 \%)$; $3.3 \%$ (95\% CI: $1.9-5.5)$ went to a territorial service because it was nearer home (36.4\%) and 2.4\% (95\% CI: 1.3-4.2) went to hospital (Figure 3; Table 5).

\section{Proposals}

According to the GPs enrolled in the study 28.9\% (95\% CI: 20.6-38.7) of the patients sampled needed further assistance, such as psychological support (25.3\%), physiotherapy (25.3\%), home care service integrated $(16.4 \%)$, social assistance $(15.1 \%)$, to go to a recreational centre $(13.3 \%)$, or needed other support such as health benefits, or to live in a protected structure like a nursing home $(4.6 \%)$.

As possible solutions to the problem of loneliness, $36.2 \%$ (95\% CI: 27.8-45) of the patients declared that they approved of nursing homes, and 17.7\% (95\% CI: $11.9-$ 20.3) had heard of the concept of a group apartment. Only $12.6 \%(95 \% \mathrm{CI}: 9.3-17.1)$ of the sample went to any kind of meeting centre: of these $30.8 \%$ went to a municipal recreational centre, $24 \%$ to a religious association, $17.9 \%$ to a university for seniors, $5.1 \%$ did voluntary work, 22.2\% were engaged in other activities (cultural, religious, recreational, etc.). 77\% (95\% CI: 69.6-83.2) were unaware of the possible existence of special services devoted to senior citizens in their residential quarter, while $60.7 \%$ (95\% CI: 51.7-69.1) would like the municipality to organize activities for senior citizens in the municipal territory. Among the possible activities, those preferred were recreational centres and meeting places (52.4\%) and services for the elderly (home care service integrated in $4.7 \%$, healthcare in 5\%, "old-sitters" like "help with shopping, buying medicines, etc." in 7\%), 31.3 other.

\section{Discussion and Conclusion}

The present study was conducted to assess the perception of healthcare of elderly patients over the age of 65 years resident in the city of Bari. It clearly depicts a fairly complex and multifaceted picture.

Although the mean age of the population under study was quite high, the general state of health was judged good both by the GPs and by the interviewed patients, as shown by the full agreement between the GPs' and their patients' opinions (79.3\% versus 76\%, aggregating all answers ranging from very good to moderate).

Instead, there was a difference between the diseases considered disabling by the patients and those referred as such by the GPs: the elderly feel "disabled" if they have difficulty in moving, or cannot see and/or hear well, while the GP considers disability to be related to difficulties in moving due to arthritis, but especially to systemic diseases such as hypertension and heart disease. The different perspective could be originated by the GPs knowledge of an objectively diagnosed health problem in the patient, while the patient himself perceives only the effects of this health problem, judging subjectively its effect on himself, such as the inability to carry any their normal activities out. 

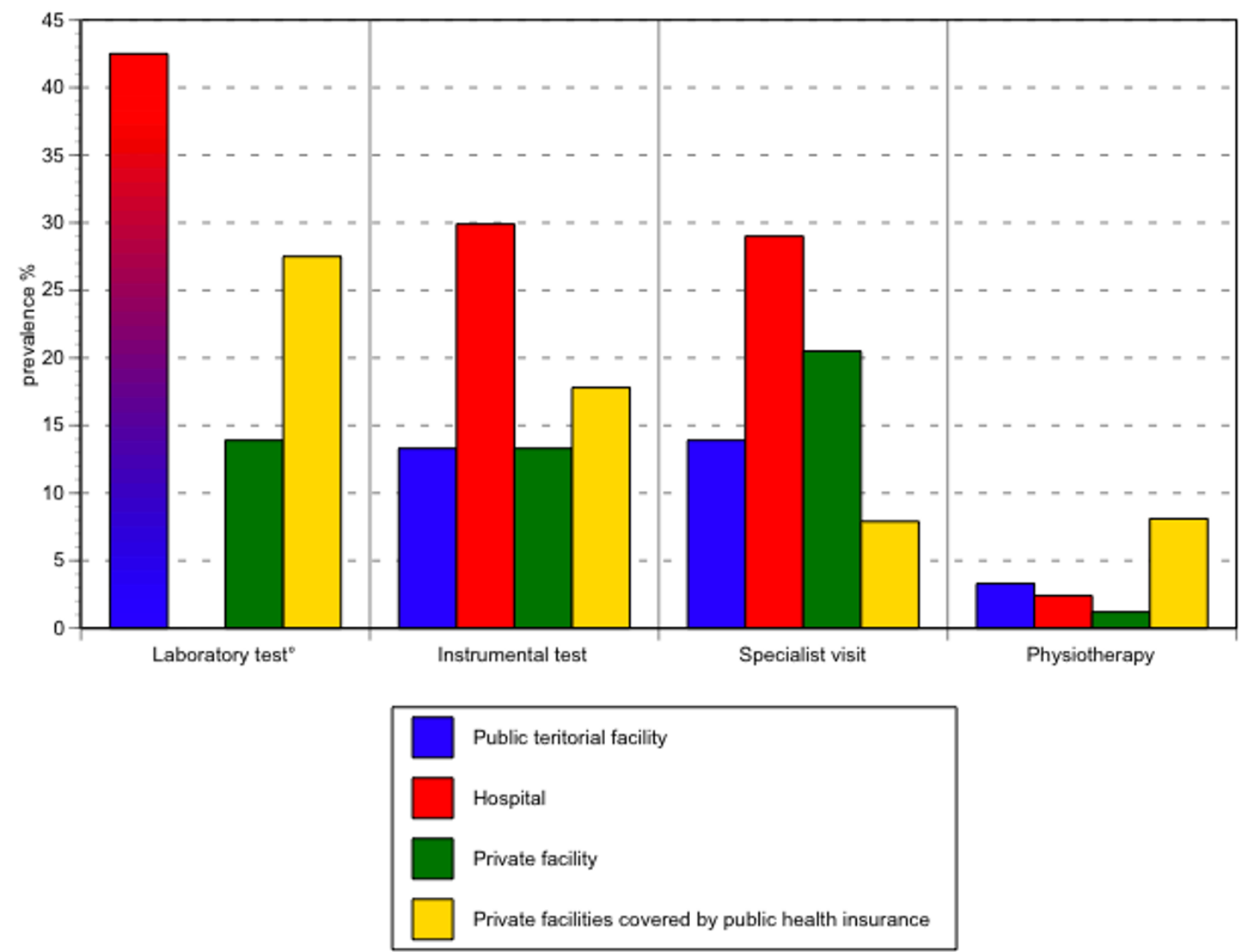

${ }^{\circ}$ For laboratory tests hospital and public facility were considered all together.

Figure 3

Percentage distribution of facilities consulted by the elderly patients interviewed, by type of procedure.

Notably, the great majority of elderly patients consider the healthcare they receive to be satisfactory (about $90 \%$ of cases aggregating answers ranging from very good to moderate). In particular, the GP is the true point of reference for this slice of the population for both strictly medical problems (83.1\%for drug prescriptions, $47.1 \%$ for known diseases, $30.5 \%$ for new diseases), and for advice (10.9\%, but $26.3 \%$ according to GPs opinions). The doctor's advice is then faithfully followed, as demonstrated also by the overall compliance with the prescribed therapy (78.2\%). Instead, the patients attributed little value to social services, which were poorly known and above all little used (7.6\%).

Public hospital facilities play a central role in second level healthcare in about $30 \%$ of cases, because they are considered more reliable. Private facilities covered by public health insurance are also considered important (used by about $15 \%$ of cases) and are preferred because they are usually nearer to home or have shorter waiting lists.

Although the importance of new contacts and mobility should be one of the targets in developing opportunities for elderly well-being [12], solutions to the issue of loneliness as a health problem are still largely lacking. Few senior citizens go to municipal facilities devoted to alleviating this problem(12.6\%), either because probably such facilities are not widespread over the territory or because two out of three patients are unaware of their existence.

Satisfaction with care in older people is determined by several social, physical and financial factors probably interacting with each other. Especially the feeling loneli- 


\begin{tabular}{|c|c|c|c|c|c|c|c|c|}
\hline \multirow[b]{2}{*}{ Laboratory tests ${ }^{\dagger *}$} & \multicolumn{3}{|c|}{ Public facility } & & \multicolumn{2}{|c|}{ Private facility } & \multicolumn{2}{|c|}{ Private facility covered by public health insurance } \\
\hline & & $N(|4|)$ & Prevalence $\%$ & & $N(46)$ & Prevalence \% & $N(91)$ & Prevalence \% \\
\hline indicated by GP & & 42 & $29,8 \%$ & & 4 & $8,7 \%$ & 26 & $28,6 \%$ \\
\hline cost less & & 11 & $7,8 \%$ & & - & - & 3 & $3,3 \%$ \\
\hline shorter waiting lists & & 12 & $8,5 \%$ & & 17 & $37,0 \%$ & 25 & $27,5 \%$ \\
\hline more confidence & & 44 & $31,2 \%$ & & 6 & $13,0 \%$ & 14 & $15,4 \%$ \\
\hline nearer home & & 30 & $21,3 \%$ & & 16 & $34,8 \%$ & 38 & $41,8 \%$ \\
\hline better treatment & & 7 & $5,0 \%$ & & 6 & $13,0 \%$ & 6 & $6,6 \%$ \\
\hline \multirow[t]{2}{*}{ only one known } & & 21 & $14,9 \%$ & & 1 & $2,2 \%$ & 17 & $18,7 \%$ \\
\hline & \multicolumn{2}{|c|}{ Public territorial facility } & \multicolumn{2}{|c|}{ Hospital facility } & \multicolumn{2}{|c|}{ Private facility } & \multicolumn{2}{|c|}{ Private facility covered by public health insurance } \\
\hline Instrumental investigations* & N (44) & Prevalence \% & N (99) & Prevalence \% & N (44) & Prevalence \% & $N(167)$ & Prevalence \% \\
\hline indicated by GP & 19 & $43,2 \%$ & 25 & $25,3 \%$ & 5 & $11,4 \%$ & 17 & $10,2 \%$ \\
\hline cost less & 5 & $11,4 \%$ & 4 & $4,0 \%$ & 1 & $2,3 \%$ & 2 & $1,2 \%$ \\
\hline shorter waiting lists & 3 & $6,8 \%$ & 20 & $20,2 \%$ & 15 & $34,1 \%$ & 21 & $12,6 \%$ \\
\hline more confidence & 8 & $18,2 \%$ & 32 & $32,3 \%$ & 17 & $38,6 \%$ & 9 & $5,4 \%$ \\
\hline nearer home & 10 & $22,7 \%$ & 14 & $14,1 \%$ & 12 & $27,3 \%$ & 16 & $9,6 \%$ \\
\hline better treatment & 2 & $4,5 \%$ & 10 & $10,1 \%$ & 5 & $11,4 \%$ & 1 & $0,6 \%$ \\
\hline only one known & 3 & $6,8 \%$ & 19 & $19,2 \%$ & 2 & $4,5 \%$ & 10 & $6,0 \%$ \\
\hline Specialist visits* & $N(46)$ & Prevalence \% & $N(96)$ & Prevalence \% & $N(68)$ & Prevalence \% & $N(26)$ & Prevalence \% \\
\hline indicated by GP & 19 & $41,3 \%$ & 27 & $28,1 \%$ & 25 & $36,8 \%$ & 7 & $26,9 \%$ \\
\hline cost less & 13 & $28,3 \%$ & 4 & $4,2 \%$ & - & - & - & - \\
\hline shorter waiting lists & 1 & $2,2 \%$ & 6 & $6,3 \%$ & 12 & $17,6 \%$ & 5 & $19,2 \%$ \\
\hline more confidence & 8 & $17,4 \%$ & 42 & $43,8 \%$ & 23 & $33,8 \%$ & 3 & $11,5 \%$ \\
\hline nearer home & 10 & $21,7 \%$ & 4 & $4,2 \%$ & 2 & $2,9 \%$ & 5 & $19,2 \%$ \\
\hline better treatment & - & - & 14 & $14,6 \%$ & 9 & $13,2 \%$ & 1 & $3,8 \%$ \\
\hline only one known & 4 & $8,7 \%$ & 15 & $15,6 \%$ & 8 & $11,8 \%$ & 2 & $7,7 \%$ \\
\hline Physiotherapy* & $N(I I)$ & Prevalence \% & $N(8)$ & Prevalence \% & $N(4)$ & Prevalence \% & $N(27)$ & Prevalence \% \\
\hline indicated by GP & 3 & $27,3 \%$ & 5 & $62,5 \%$ & 3 & $75,0 \%$ & 6 & $23,1 \%$ \\
\hline cost less & - & - & 4 & $50,0 \%$ & - & - & 2 & $7,7 \%$ \\
\hline shorter waiting lists & 3 & $27,3 \%$ & - & - & - & - & - & \\
\hline more confidence & - & - & I & $12,5 \%$ & 4 & $100,0 \%$ & 4 & $15,4 \%$ \\
\hline nearer home & 4 & $36,4 \%$ & - & - & I & $25,0 \%$ & 10 & $38,5 \%$ \\
\hline better treatment & 3 & $27,3 \%$ & - & - & I & $25,0 \%$ & 3 & $11,5 \%$ \\
\hline only one known & 3 & $27,3 \%$ & - & - & - & - & 4 & $15,4 \%$ \\
\hline
\end{tabular}

tFor laboratory tests, hospital and public facility were considered all together.

*Multiple-choice answers were possible. 
ness, the degree of self-care capacity, poor overall health, anxiety, and sometimes poor financial resources are factors to be considered in the care of this specific population in order to preserve or improve their quality of life [13].

Decision makers therefore need to create services supporting the key role played by GPs, who, although conscious of the importance of the part they play in caring for the elderly, are also well aware that their assistance is not sufficient to satisfy their health needs. The real needs of this population could be guaranteed only by a continuous interchange and effective collaboration among the various healthcare facilities and social assistance-figures present throughout the territory.

\section{List of abbreviations}

GPs: General Practitioners

\section{Competing interests}

The author(s) declare that they have no competing interests.

\section{Authors' contributions}

AF and AP carried out the survey and drafted the manuscript. RP and DM have made substantial contributions to conception and design of the study and performed the statistical analysis. CAG, PLL and MQ conceived the study as well as participating in its design and coordination.

All authors have read and approved the final manuscript.

\section{Acknowledgements}

This study was supported by Assessorato alle Politiche Sociali of Bari, Dr. Antonio Bisceglie.

We thank all General Practitioners who collaborated to the survey for their invaluable help: A Lampugnani, C De Mola, M De Niccolò, S Della Queva, V Frappampina, F Lampugnani, V Melodia, E Pirrelli, M Sannicandro, A Saracino, F Savino, F Smacchia, M Tarallo, F Trotta.

\section{References}

I. Bertozzi N, Vitali P, Binkin N, Perra A, D'Argenio P: "Quality of life" of the elderly population: a survey to evaluate elderly people's self -perceived health in II Italian regions (Argento Study, 2002). Ig Sanita Pubbl 2005, 6 I (6):545-59.

2. Palomba R, Misiti M, Sabatino $D$ : La vecchiaia può attendere. Immagini, aspettative e aspirazioni degli anziani italiani. Demotrends 2001:1-72.

3. Istituto Nazionale di Statistica: Cause di morte: anno 2002 Roma; 2005.

4. Ministero della Salute della Repubblica Italiana: Verso un piano di azioni per la promozione e la tutela della salute della donna e del bambino Roma; 2007.

5. Istituto Nazionale di Statistica: Rapporto Annuale - La situazione del Paese nel 2005. Roma 2006.

6. Maggi S, Farchi G, Crepaldi G: Epidemiologia della cronicità in Italia. In Rapporto Sanità 200 I Edited by: Falcitelli N, Trabucchi M, Vanara F. Bologna: II Mulino; 200I:103-2I.

7. Pahkala K, Kivela SL, Laippala P: Social and environmental factors and dysthymic disorder in old age. J Clin Epidemiol 1992, 45(7):775-83.

8. Grimby A, Svanborg A: Morbidity and health-related quality of life among ambulant elderly citizens. Aging 1997, 9(5):356-64.
9. Jinks $\mathrm{C}$, Jordan $\mathrm{K}$, Croft $\mathrm{P}$ : Osteoarthritis as a public health problem: the impact of developing knee pain on physical function in adults living in the community: (KNEST 3). Rheumatology 2007, 46(5):877-8I.

10. Gillespie LD, Gillespie WJ, Robertson MC, Lamb SE, Cumming RG, Rowe $\mathrm{BH}$ : Interventions for preventing falls in elderly people. Cochrane Database Syst Rev 2003:CD000340.

II. Saint-Jean O, Berigaud S, Bouchon JP: Polypathology and co-morbidity: a dynamic way for describing morbidity in aged patients. Study of 100 patients, aged 80 and over, in a shortstay geriatric internal medicine unit. Ann Med Interne I991, | 42(8):563-9.

12. Cohen-Mansfield J, Parpura-Gill A: Loneliness in older persons: a theoretical model and empirical findings. Int Psychogeriatr 2007, I 9(2):279-94.

13. Borg C, Hallberg IR, Blomqvist K: Life satisfaction among older people $(65+)$ with reduced self-care capacity: the relationship to social, health and financial aspects. I Clin Nurs 2006, 15(5):607-18.

14. Non aver paura dell'età che avanza [http://www.irpps.cnr.it/ eventi/anziani.pdf]

15. Schäfer UB: Quality of life of the elderly is underestimated. Krankenpfl Soins Infirm 2005, 98(2): I4-6.

16. Khaw KT: Epidemiological aspects of ageing. Philos Trans $R$ Soc Lond B Biol Sci 1997, 352(1363):1829-35.

17. Anziani: quali bisogni da soddisfare? [http://www.epicen tro.iss.it/focus/anziani/anziani-bisogni.asp]

18. Paccagnella B: General practitioner and family practitioner are not synonyms: what is the difference? Ig Sanita Pubbl 2006, 62(I):91-7.

19. Wilkinson D, Stave C, Keohane D, Vincenzino O: The role of general practitioners in the diagnosis and treatment of Alzheimer's disease: a multinational survey. J Int Med Res 2004, 32(2): $149-59$

20. De Berardis G, Pellegrini F, Franciosi M, Belfiglio M, Di Nardo B, Greenfield S, Kaplan SH, Rossi MC, Sacco M, Tognoni G, Valentini M, Nicolucci A, QuED Study: Quality of care and outcomes in type 2 diabetic patients: a comparison between general practice and diabetes clinics. Diabetes Care 2004, 27(2):398-406.

21. Roncaglioni MC, Avanzini F, Roccatagliata D, Monesi L, Tamayo-Benitez D, Tombesi M, Caimi V, Longoni P, Lauri D, Barlera S, Tognoni G, Collaborative Group Risk and Prevention Study: How general practitioners perceive and grade the cardiovascular risk of their patients. Eur J Cardiovasc Prev Rehabil 2004, I I (3):233-8.

22. Katz S, Downs TD, Cash HR, Grotz RC: Progress in development of the index of ADL. Geronotologist 1970, 10:20-30.

23. Scanlan J, Borson S: he Mini-Cog: receiver operating characteristics with expert and naive raters. Int J Geriatr Psychiatry 200I, 16:T216-22.

24. Borson S, Scanlan J, Brush M, Vitaliano P, Dokmak A: The mini-cog: a cognitive 'vital signs' measure for dementia screening in multi-lingual elderly. Int J Geriatr Psychiatry 2000, I 5: I 02I-7.

25. American College of Sports Medicine Position Stand: Exercise and physical activity for older adults. Med Sci Sports Exerc 1998, 30:992-1008

26. Lemeshow S, Stroh G: Sampling Techniques for Evaluating Health Parameters in Developing Countries. Board on Science and Technology for International Development (BOSTID) working paper Washington, DC: National Academy Press; 1988.

27. Demografia in cifre [http://www.demo.istat.it/]

\section{Pre-publication history}

The pre-publication history for this paper can be accessed here:

\section{http://www.biomedcentral.com/1472-6963/7/174/pre} pub 